\title{
Continuing education for primary health care nurse practitioners in Ontario, Canada
}

\author{
Pamela Baxter $^{\text {a,* }}$, Alba DiCenso ${ }^{\text {b,c,1 }}$, Faith Donald ${ }^{\text {d,2 }}$, Ruth Martin-Misener ${ }^{\text {e,3 }}$, \\ Joanne Opsteen ${ }^{\mathrm{f}, 4}$, Tracey Chambers ${ }^{\mathrm{g}, 5}$ \\ a School of Nursing, McMaster University, 1280 Main Street West, Room HSC 3N28C, Hamilton, ON, Canada L8S 4K1 \\ ${ }^{\mathrm{b}}$ Nursing and Clinical Epidemiology and Biostatistics, CHSRF/CIHR Chair in Advanced Practice Nursing, McMaster University, Hamilton, ON, Canada \\ c Ontario Training Centre in Health Services \& Policy Research, McMaster University, 1280 Main Street West, Room HSC 3N25B, Hamilton, ON, Canada L8S 4K1 \\ d Daphne Cockwell School of Nursing, Ryerson University, 350 Victoria Street, Office POD 464C, Toronto, ON, Canada M5B 2K3 \\ e Dalhousie University, School of Nursing, 5869 University Ave, Forrest G09, Halifax, NS, Canada B3H 4R2 \\ f PHCNP Program, York University, School of Nursing E PHCNP East End Community Health Centre, 1619 Queen Street East, Toronto, ON, Canada M4L1G4 \\ ${ }^{g}$ McMaster University, School of Nursing, 1280 Main Street West, Hamilton, ON, Canada L8S 4K1
}

\section{A R T I C L E I N F O}

\section{Article history:}

Accepted 23 July 2012

\section{Keywords:}

Continuing education

Nurse practitioners

Online-education

Nursing student

Nursing

\begin{abstract}
S U M M A R Y
The Council of Ontario University Programs in Nursing offers a nine-university, consortium-based primary health care nurse practitioner education program and on-line continuing education courses for primary health care nurse practitioners. Our study sought to determine the continuing education needs of primary health care nurse practitioners across Ontario, how best to meet these needs, and the barriers they face in completing continuing education. Surveys were completed by 83 (40\%) of 209 learners who had participated in continuing education offered by the Council of Ontario University Programs in Nursing between 2004 and 2007. While 83\% $(n=50)$ of nurse practitioners surveyed indicated that continuing education was extremely important to them, they also identified barriers to engaging in continuing education offerings including; time intensity of the courses, difficulty taking time off work, family obligations, finances and fatigue. The most common reason for withdrawal from a continuing education offering was the difficulty of balancing work and study demands. Continuing education opportunities are important to Ontario primary health care nurse practitioners, and on-line continuing education offerings have been well received, but in order to be taken up by their target audience they must be relevant, readily accessible, flexible, affordable and offered over brief, intense periods of time using technology that is easy to use and Internet sites that are easily navigated.
\end{abstract}

(c) 2012 Elsevier Ltd. All rights reserved.

\section{Introduction}

In 1997, Ontario was one of the first provinces in Canada to enact legislation to introduce the nurse practitioner (NP) role (Kaasalainen et al., 2010). As of 2010, 1486 NPs were employed in nursing in Ontario, an increase of $32.7 \%$ over 2009 (College of Nurses of Ontario [CNO], 2010a). Ontario NPs represent over half the 2500 NPs in all of Canada (Kaasalainen et al., 2010). With this rapid growth, the issue of how to ensure that NP practice remains safe and responsive to the changing health care needs of Canadians within an ever-changing health care system becomes extremely important. This study sought to explore

\footnotetext{
* Corresponding author. Tel.: +1 905525 9140x22290; fax: + 19055218834. E-mail addresses: baxterp@mcmaster.ca (P. Baxter), dicensoa@mcmaster.ca (A. DiCenso), fdonald@ryerson.ca (F. Donald), ruth.martin-misener@dal.ca

(R. Martin-Misener), jopst@np-education.ca (J. Opsteen), chambt@mcmaster.ca (T. Chambers).

1 Tel.: + 1905525 9140x22277; fax: + 19055245199 .

2 Tel.: + 1416979 5000x6309; fax: + 14169795332 .

3 Tel.: +1 902494 2250, +1 902494 2535; fax: +1 9024943487

4 Tel.: + 1416778 5858; fax: +1 4167785855 .

5 Tel.: + 1905525 9140x21431; fax: + 19055218834 .
}

Ontario NP perceptions of their CE learning needs, the most effective method of course delivery, and to determine the general barriers to $\mathrm{CE}$.

\section{Background}

NPs are prepared with advanced knowledge and decision-making skills which enable them to assess and promote health, treat and prevent disease and injury, and provide rehabilitation and support to individuals, families and communities (CNO, 2008). They specialize in Adult, Pediatric, or Primary Health Care (Koren et al., 2010). In enacting their role, NPs autonomously perform controlled acts that are outside the registered nurse's scope of practice. These acts include; communicating a diagnosis to the patient, prescribing approved drugs, and ordering diagnostic tests (CNO, 2008). NPs practice in both the acute care and primary health care sectors, i.e., physician's offices, family health teams, and community health centres (CNO, 2008) and provide vital access to primary health care services in isolated, underserved, remote and rural communities where shortages of primary care physicians are compounded by issues of poverty, unemployment and poor education (DiCenso et al., 2007; Tilleczek et al., 2005). They often work with specific patient populations (e.g., those with mental illness) that require 
specialized knowledge. In a 2008 survey of 378 primary health care NPs (PHC-NPs), (Koren et al., 2010) about half of respondents reported caring for people who were unemployed (50\%), or substance users (46\%). While acute care NPs across Canada must complete graduate level education, PHC-NP education may include post-baccalaureate or master's level preparation (Martin-Misener et al., 2010). Given that NPs are autonomous practitioners who provide care to patients with diverse health issues, it is essential that they maintain and update their knowledge and skills through $\mathrm{CE}$.

An ongoing commitment by Ontario to ensure safe NP practice resulted in an innovative approach to NP education. In 1995, the Council of Ontario University Programs in Nursing (COUPN) established a nine-university consortium which offers one NP curriculum across all universities, primarily through distance education. The goal of this consortium is to promote efficiency, increase accessibility, and to ensure a consistent program for students (van Soeren et al., 2000). The consortium offers a PHC-NP post-baccalaureate certificate and a master's degree program that includes five core graduate level PHC-NP courses: pathophysiology, roles and responsibilities, advanced health assessment and diagnosis, therapeutics, and integrative practicum. These courses, in addition to general master's level courses, must be completed within two calendar years.

From 2004 to 2007, the Ontario Ministry of Health and Long-Term Care provided funding to COUPN to offer five CE courses (Table 1). Each 13-week course was offered on-line in English and French using a self-study format, with explicit learning objectives, assigned readings, a reference list of relevant learning resources, and using a variety of distance education modalities, e.g., web-based newsgroups, facilitated teleconference discussions, and individual on-line knowledge and skill-testing activities. All courses consisted of 11 learning modules (i.e., learning materials/activities), with the exception of the pharmacotherapeutics course which consisted of 13 modules. Learners were given one week to complete each learning module. In the final two weeks of a full course all learners, with the exception of those in the pharmacotherapeutics course, completed an on-site objective structured clinical evaluation (OSCE) to demonstrate the application of their knowledge and skills and received a certificate upon successfully completing the course and OSCE. To provide flexibility in meeting their interests and learning needs, learners were free to enrol in a full 13-week course or in one or more individual modules that broke the full courses down into week-long segments.

In comparison to the volume of literature published on the continuing education needs of registered nurses, very little has focused on the continuing education needs of advanced practice nurses, and particularly PHC-NPs, in Canada. A search of Medline, EMBASE, and CINAHL databases for recent literature related to continuing education for nurse practitioners in Canada was conducted using the search terms, nurse practitioner; advanced practice nurse; education, nursing; education, continuing; education, nursing, continuing, and Canada. All searches were limited to literature published in English between 1995 and 2010. This search only revealed one relevant Canadian study (Tilleczek et al., 2005) and this study did not address the specific CE needs of the

Table 1

COUPN's NP continuing education courses.

\begin{tabular}{|c|c|}
\hline Course & Focus \\
\hline $\begin{array}{l}\text { Rural and remote } \\
\text { health care }\end{array}$ & $\begin{array}{l}\text { Assessment and management of clients with urgent or } \\
\text { emergent health issues }\end{array}$ \\
\hline Pharmacotherapeutics & $\begin{array}{l}\text { Optimal pharmacological (and non-pharmacological) } \\
\text { treatment and prevention of acute and chronic conditions }\end{array}$ \\
\hline $\begin{array}{l}\text { Issues in mental } \\
\text { health }\end{array}$ & $\begin{array}{l}\text { Assessment and management of clients presenting with } \\
\text { mental health concerns }\end{array}$ \\
\hline $\begin{array}{l}\text { Fundamentals of } \\
\text { primary health care }\end{array}$ & $\begin{array}{l}\text { Standards and practices required to provide primary } \\
\text { health care to populations }\end{array}$ \\
\hline Care of the older adult & Older adult care and support of healthy ageing \\
\hline
\end{tabular}

$\mathrm{NP}$, rather, it discussed the importance of CE to NPs. Tilleczek et al. (2005), in a pilot study of the CE needs of NPs working in rural and northern Ontario, found that almost all respondents (95\%) rated CE as either "very important" or "extremely important". Unfortunately, NP participation in CE activities was hindered by "distance to travel" and "expense to travel". By extending the literature to international studies we were able to find data that may be transferred to the Canadian context. For example, Friedlander (2006), in a study to examine the factors related to NP participation in on-line continuing nursing education mailed a survey to a random sample of 1000 RN/NPs in Massachusetts in the United States. This survey (which had a $42 \%$ response rate) revealed that NPs do not participate in CE activities due to a lack of time and a preference for face-to-face learning. In 1995, Sheperd reported on the training needs of qualified NPs in the United Kingdom. Using a descriptive survey of 6300 NPs he found that NPs did not have support from managers to engage in professional development which often led to low staff morale. Seventy-four percent of Sheperd's sample stated that they preferred CE opportunities that were offered over full single days or multiple full days. Extending the search to include RN continuing education revealed an integrative review by Schweitzer and Krassa (2010), which sought to explore the deterrents to nurses' participation in continuing professional development. In contrast to the findings from Friedlander (2006) and Tilleczek et al. (2005), this review of ten research studies (nine of which were a quantitative, descriptive research design), found that the most frequent deterrents were the cost of attending $\mathrm{CE}$, the inability to get time off work to attend, and home and childcare responsibilities. It is unclear whether the same deterrents are present for NPs as each group's work demands may be different in nature. For example, the RN may work primarily 12-hour shifts, may work in highly acute areas and work with a larger team of health care professionals. In contrast, the NP would work primarily 8-12 hour shifts but in a less highly acute work environment, may work with a smaller team of health care professionals and may have more autonomy and wider scope of practice. In order to specifically explore CE from the NP's perspective additional research was necessary. The purpose of our study was two-pronged: 1) to explore NP perceptions of their CE learning needs and the most effective method of course delivery, and 2) to determine the general barriers to NP CE.

\section{Methods}

The study received full approval from the Faculty of Health Sciences Research Ethics Board at McMaster University prior to implementation. Informed consent was obtained from all study participants. An on-line questionnaire was developed for distribution to all PHC-NPs who had enrolled in one or more of the five CE courses offered between 2004 and 2007. A cross-sectional survey method provided a means of obtaining data quickly, from eligible participants across the province, and was modeled after a pre-existing study that focused on CE activities of NPs in northern Ontario. Before its launch, the survey was pilot tested by six PHC-NPs for content, flow and readability and changes were made based on the feedback received. The final survey included 23 questions and took approximately 15 minutes to complete.

In addition to demographic questions regarding their work experience and educational achievements, participants were asked about their experiences with the COUPN NP CE courses; specifically, the courses in which they had enrolled and completed (or not), their overall impressions of the courses, the barriers they experienced in taking and completing the courses and $\mathrm{CE}$ in general, other $\mathrm{CE}$ activities in which they had engaged, and their preferred method of completing $\mathrm{CE}$ courses. For most questions, participants were asked to select from a list of possible responses, which included an opportunity to provide an alternate, narrative response when necessary. Eligible NPs were sent the website address along with a personal username and password which enabled them to access and complete the survey. 
Data were analysed using the Statistical Package for Social Sciences, version 17.0. The analysis was based on frequency tables for categorical and nominal data and descriptive statistics for continuous data.

\section{Results}

Of 209 learners surveyed, 83 (40\%) responded; $72 \%(n=60)$ of these were NPs, i.e. a registered nurse in the extended class or RN(EC), $18 \%$ $(n=15)$ were non-RN(EC)s, and $10 \%(n=8)$ did not identify their registration status. The fact that the title Nurse Practitioner only became a protected title in Ontario in August 2007 (to be used only by those in the Extended Class) may have led to confusion for some of the potential participants which led to $28 \%$ of the sample completing the survey even though they were no longer formally recognized as an NP (Health Force Ontario, 2009). The following results are based on data collected from those who identified $\mathrm{RN}(\mathrm{EC})$ registration status $(\mathrm{N}=60)$.

Ninety percent $(90 \%, n=54)$ of NPs worked in primary health care settings, $72 \%(n=43)$ of whom were employed in permanent, full-time positions. Most had completed the COUPN NP (post-baccalaureate) certificate program $(73 \%, \mathrm{n}=44)$. Respondents reported a mean of 18.3 years of experience as an $\mathrm{RN}(\mathrm{n}=60)$, and a mean of 7.9 years of experience as an NP $(n=53)$. The majority of NPs were female $(88 \%$, $n=53)$.

\section{Perceived NP CE learning needs}

To plan future CE opportunities, it is important to understand where the greatest demand lies. In this study, the majority of NPs had enrolled in the Pharmacotherapeutics course $(75 \%, n=45)$, followed by Care of the Older Adult $(25 \%, \mathrm{n}=15)$ and the Rural and Remote Health Care $(22 \%, n=13)$. This may reflect a concern for patient safety and professional liability in conjunction with a recognized knowledge deficit, an ever-changing pharmaceutical landscape, and an aging population. In contrast, the lowest proportion of respondents had enrolled in the Mental Health in Primary Health Care course $(10 \%, n=6)$. NPs indicated that, if offered, they would be interested in CE courses that address the interpretation of laboratory and diagnostic tests $(82 \%, n=49)$, pain control strategies $(62 \%, \mathrm{n}=37)$, prescribing narcotic medications (52\%, $n=31)$, and early detection and screening for cancer $(48 \%, n=$ 29). When asked about other CE activities or courses not offered by COUPN that they had engaged in since 2004, pharmaceutical company sponsored dinners $(65 \%, \mathrm{n}=39$ ) were most common, followed by conferences, i.e., provincial/regional conferences sponsored by the Nurse Practitioners' Association of Ontario (NPAO) $(53 \%, n=32)$ and Primary Care Today/Primary Care UPDATES $(43 \%, \mathrm{n}=26)$, i.e., intensive, two-day medical education conferences held across Canada, offering case-based learning programs for family physicians and other primary care professionals.

\section{Course delivery and uptake}

Those who completed the survey described how they preferred to engage in CE activities. The majority $(73 \%, \mathrm{n}=44)$ of respondents preferred an on-line, self-directed format for CE courses. Also popular were intensive learning opportunities such as two-day workshops $(55 \%, n=33)$, an on-line lecture series $(53 \%, n=32)$ and conferences $(48 \%, n=29)$. Classroom lectures were the least preferred method of CE course delivery $(17 \%, \mathrm{n}=10)$.

\section{Barriers to continuing education}

Most NPs $(83 \%, n=50)$ indicated that CE was extremely important to their NP practice and $60 \%(n=36)$ denied experiencing any barriers to participating in COUPN's CE courses. For those who did encounter barriers to participating in COUPN's NP CE courses, the top five were identified as: [courses are] time intensive ( $50 \%, \mathrm{n}=12 / 24)$; difficult to get time off work and/or away from patient care $(33 \%, n=8 / 24)$; family obligations (time away from family) $(33 \%, n=8 / 24)$; lack of finances and/or financial support (29\%, $n=7 / 24)$; and fatigue $(21 \%, n=5 / 24)$.

A closer look was taken at the barriers reported by learners who completed some or none of the full courses in which they had enrolled $(\mathrm{n}=14)$, and the barriers reported by learners who completed all of the full courses in which they had enrolled $(n=14)$ (Table 2). Barriers were reported in similar proportion by each group, with the exception of "lack of information about CE offerings" which was reported as a barrier by more learners who had completed all of the full courses in which they had enrolled, than learners who had completed some or none of the courses in which they had enrolled. "Lack of access to distance education technology requirements" was reported more frequently by those who completed some or none of the full courses in which they had enrolled. The barrier most frequently reported by both groups was "courses are time intensive". "Other" barriers reported by learners who had completed some or none of the courses in which they enrolled included, rigid timeframes and dial-up Internet at home. "Other" barriers reported by learners who completed all of the courses in which they enrolled included, a preference for the modular format, and "courses were full quickly".

\section{Discussion}

Continuing education is necessary if NPs are to continue to provide competent patient care. The fact that the NPs who participated in this study continue to access CE opportunities suggests that this group of highly skilled health care professionals is making a conscious effort to continuously improve their critical thinking and clinical reasoning skills; thereby promoting patient safety. This effort is essential as, with the ever-increasing complexity of patient care, there are more opportunities for errors to occur in decision-making with potentially negative and, at times, fatal results for patients (Cruz et al., 2009).

Understanding the CE needs of NPs is imperative. A large proportion of the participants in this study indicated an interest in CE that addressed how to interpret laboratory and diagnostic tests, as well as pain control and prescribing narcotics. While this could reflect that NPs perceived their formal education in these areas to be lacking, or their diligence in promoting safe practice and preventing errors, it

Table 2

Barriers to completing full courses.

\begin{tabular}{|c|c|c|}
\hline \multirow[t]{2}{*}{ Response } & \multirow{2}{*}{$\begin{array}{l}\text { Completed some or } \\
\text { none of full course(s) } \\
(\mathrm{n}=14) \\
\%\end{array}$} & \multirow{2}{*}{$\begin{array}{l}\text { Completed all of } \\
\text { full course }(\mathrm{s}) \\
(\mathrm{n}=14) \\
\%\end{array}$} \\
\hline & & \\
\hline Courses are time intensive & 42.9 & 71.4 \\
\hline $\begin{array}{l}\text { Family obligations (time away from } \\
\text { family) }\end{array}$ & 35.7 & 35.7 \\
\hline Other & 35.7 & 14.3 \\
\hline $\begin{array}{l}\text { Difficulty taking time off work and/ } \\
\text { or away from patient care }\end{array}$ & 28.6 & 35.7 \\
\hline $\begin{array}{l}\text { Lack of finances and/or financial } \\
\text { support }\end{array}$ & 28.6 & 21.4 \\
\hline Fatigue & 28.6 & 21.4 \\
\hline $\begin{array}{l}\text { Lack of access to distance education } \\
\text { technology requirements (e.g., } \\
\text { Internet, teleconferencing, virtual } \\
\text { classroom, webcam) }\end{array}$ & 21.4 & 7.1 \\
\hline $\begin{array}{l}\text { Lack of information about CE } \\
\text { offerings }\end{array}$ & 14.3 & 28.6 \\
\hline $\begin{array}{l}\text { Lack of access to (or difficulty } \\
\text { accessing) educational resources } \\
\text { (e.g. library) }\end{array}$ & 14.3 & 14.3 \\
\hline $\begin{array}{l}\text { Lack of CE topics and/or courses rel } \\
\text { evant to my needs }\end{array}$ & 14.3 & 14.3 \\
\hline $\begin{array}{l}\text { Difficulty learning in an on-line } \\
\text { format }\end{array}$ & 7.1 & 7.1 \\
\hline
\end{tabular}


could also be an indication of the NPs' length of time in clinical practice. A U.S. study by Green et al. (2005) found that the CE needs of NPs become more complex with length of time in practice. More novice NPs (i.e., those in practice for less than one year) were interested in CE related to clinical assessment, while those with more than 10 years of experience expressed a need for $\mathrm{CE}$ in advanced diagnostic skills and disease management strategies (Green et al., 2005). The authors suggested that length of time in practice should be factored in when marketing CE opportunities to NPs. If we consider that many of the NPs in the current study were interested in CE related to pharmacotherapeutics and had attended pharmaceutical sponsored educational activities (e.g. Lunch and Learns) then it is important to discuss who should deliver this education, as well.

It is likely that the demand for CE opportunities related to prescribing medication will increase among Ontario NPs with the passing of Bill 179 (Regulated Health Professions Law Statute Amendment Act, 2009). Under this new legislation PHC-NPs have increased authority to prescribe drugs (except for controlled drugs and substances, such as opiates) and treatments (CNO, 2010b). A national on-line survey of Australian NPs $(n=68)$ who hold prescriptive authority found that CE related to medication updates and legislative requirements for prescribing were considered very important by respondents (Newman et al., 2009).

How best to offer CE activities to NPs was described by the participants. When we consider that NPs are scattered throughout the province, it is not surprising that the majority of respondents to the current survey overwhelmingly preferred an on-line, self-directed format to all other methods of engaging in CE. It is likely that they appreciate the convenience and accessibility that on-line course delivery provides when balancing multiple demands on their time, as suggested by Friedlander (2006) and Mancuso-Murphy (2007).

The use of web-based technologies to facilitate the delivery of instruction and resources by educators to learners in distant locations has become increasingly popular (Kleinpell and Bruinsma, 2010; Southernwood, 2008). Several advantages to web-based distance learning have been cited in recent literature, including cost-effectiveness, and increased control, convenience, and flexibility for the learner (Kleinpell and Bruinsma, 2010; Southernwood, 2008). Recent literature also demonstrates that web-based CE opportunities promote life-long learning and professional development (Southernwood, 2008) and thus assist in retaining and maintaining a safe and competent health workforce (Penz et al., 2007).

According to Ruiz et al. (2006), e-learning allows learners to gain knowledge and skills faster than traditional didactic learning and thus, is more efficient and improves learner motivation. In a self-reported survey of a randomly selected sample $(n=411)$ of RN/NPs in Massachusetts, Friedlander (2006) found that participation in on-line continuing nursing education is related to convenience, i.e., it eliminated the need for travel and allowed the learner to learn at any hour, and in any location. This led the author to propose that NPs choose CE activities that best fit with their schedule.

The current study findings are similar to those of an integrative review of nursing literature on RN and non-RN students' perspectives on distance education by Mancuso-Murphy (2007), which included 12 mostly qualitative research studies conducted between 2001 and 2006 , and a dissertation completed in 1998. The review found that convenience, accessibility, and reliable technology were important factors in student satisfaction with distance education, while feelings of isolation were negatively correlated with satisfaction. In the current study, the use of technology facilitated the incorporation of various distance education modalities, such as web-based newsgroups, teleconference discussions and web-based learning activities which afforded our sample of experienced NPs the opportunity to learn from other learners.

However, those who prefer distance education, and therefore seek out these opportunities, may be overrepresented in this study. Successful on-line learners are identified in the literature as those who are self-directed, self-motivators, who possess diverse study and decisionmaking skills, and who are able to identify their own learning needs, manage their time, and actively plan to achieve their learning objectives (Mancuso-Murphy, 2007).

Respondents' interest in intensive CE learning opportunities that are delivered in short bursts, such as workshops, conferences, or Lunch and Learn-type activities, also reflects that this group of learners is interested in getting the 'biggest bang for their buck' when it comes to CE. This finding is congruent with early research by Sheperd (1995), which identified that effective CE for NPs is flexible and encompasses short blocks of study that relate to current practice.

The most common barriers to participating in CE offerings described by participants were time pressures (i.e., time intensity of the courses, difficulty taking time off work, time away from family), lack of finances/financial support, and fatigue. Similar findings were identified in previous evaluations of PHC-NPs in rural and northern Ontario, conducted by the Centre for Rural and Northern Health Research (CRaNHR, 2006). The time demands involved in completing a course could explain why some NPs preferred to complete specific one-week modules versus a full 13-week course.

Various time pressures are cited in the literature as barriers to nurses' participation in CE activities, including a lack of time to leave the work setting, and time associated with travel and family obligations (Penz et al., 2007; Schweitzer and Krassa, 2010; Tilleczek et al., 2005). In her survey of NP participation in on-line continuing nursing education in Massachusetts, Friedlander (2006) found that a lack of time for CE activities was often cited as a deterrent. Similarly, in a postal survey of nurses (i.e., registered and enrolled; and nursing assistants) in Queensland, Australia, Hegney et al. (2010) found that a lack of employer support, family commitments, staffing levels/workloads and lack of funds were barriers to CE for Australian nurses. Interestingly, one barrier not mentioned was fatigue. However, in their national survey of 3933 registered nurses living in rural and remote locations of Canada (most of whom held a diploma in nursing), Penz et al. (2007) found that nurses who were middle-aged, unmarried and working full-time were more likely to report barriers to $\mathrm{CE}$. If we consider that the sample in the current study included NPs who were working full-time and who had family responsibilities in conjunction with heavy workloads, it stands to reason that fatigue would emerge as a barrier to CE in the current study. Unfortunately, many of the aforementioned barriers have been discussed in the literature for many years.

Overall, this study served as a valuable opportunity to identify CE learning needs and preferred methods of CE delivery among practicing NPs in Ontario, and thus will contribute to maintaining a competent health workforce. In identifying the barriers and challenges involved in completing CE offerings, the findings and recommendations from this study will help to improve future CE courses and course delivery. This study also had limitations, including a small sample size and low response rate. Possible explanations for the survey's low response rate include, a lack of time, survey fatigue (as NPs receive a large number of surveys), and a lack of interest from those who enrolled in courses in 2004 (i.e., due to the passage of time). The on-line survey was developed through a service that stored the data on-site, but also required the additional step of providing personalized usernames and passwords to interested participants. This limited respondents' immediate access to the survey, and likely negatively affected its completion. Selection bias may have resulted in only those who were least or most happy with the courses completing the survey. The results of this study must also be interpreted in light of the fact that the psychometric properties of the on-line survey tool were not tested prior to data collection.

Findings from this research have implications for nurse educators, nursing practice and nursing policy. First, NP educators who are responsible for the development of $\mathrm{CE}$ activities must ensure that $\mathrm{CE}$ curricula are developed in a user-friendly manner that enables the end user to readily access the content and related supports on-line. 
It also requires that $\mathrm{CE}$ curricula be relevant to practice and reflect changes in role demands (e.g. the introduction of Bill 179) while also considering NP time constraints. Educators should ensure that opportunities for CE are offered in short, intense bursts rather than over long periods of time. When possible, opportunities must be created for NPs to engage in face-to-face meetings as this is their preferred method of learning if some of the aforementioned barriers are removed. To alleviate the barriers related to time and distance, consideration should be given to the use of virtual meetings/lunch and learns, podcasts (Stoten, 2007), wikis and blogs (Billings, 2009). While educators must ensure that $\mathrm{CE}$ is readily accessible and relevant, administrators in PHC settings must be responsible to provide release time for NPs to engage in CE activities. Such activities would promote patient satisfaction, patient safety and NP job satisfaction. However, this cannot occur unless attending such events is deemed mandatory. Therefore, at the policy level, there is a need to mandate NP CE activities in order for NPs to maintain practice competencies during a time of rapid role development. Currently, in Canada, NP CE activities are self-reported, not formally tracked.

\section{Conclusion}

Continuing education for NPs is extremely important to the practitioner, the practice setting, and the patient. CE is valued by NPs but barriers exist that preclude their participation in CE activities. Findings suggest that PHC-NPs are seeking opportunities to engage in CE to support their practice in a variety of areas that reflect increasingly complex patient care needs. Unfortunately, meeting these educational needs is challenging due to several personal and contextual barriers, the most common being: time pressures (i.e., time intensity of the courses, difficulty taking time off work, time away from family), lack of finances/ financial support, and fatigue. These barriers may reflect that this role is held primarily by women who are trying to balance work-life and family demands. However, a lack of time and a lack of financial support may also reflect a work environment that does not value $\mathrm{CE}$ and may not recognize the peril that patients are placed in when $\mathrm{CE}$ is not engaged in by NPs. Efforts must be made at the individual NP level, the organization level, and by policy makers to ensure that relevant NP activities are readily available and that time is provided by organizations to those wishing to participate.

\section{Acknowledgements}

The authors wish to thank the CHSRF/CHIR Chair in Advanced Practice Nursing for its assistance with the implementation of this study. Special thanks is also extended to all NPs who for taking time to participate in the survey and for their valuable feedback. This study was made possible by funding from the Ontario Ministry of Health and Long-Term Care (Grant \#06416). The Ontario Ministry of Health and Long-Term Care had no involvement in the study design, collection, analysis or interpretation of data, final report writing, or decision to submit the paper for publication.
Centre for Rural and Northern Health Research, 2006. Primary Health Care Nurse Practitioner Tracking Study. Laurentian University.

College of Nurses of Ontario, . Registration. Who are the RN(EC)s? Fact Sheet Retrieved from http://www.cno.org/docs/reg/45025_fsExtendedclass.pdf.

College of Nurses of Ontario, a. Membership Statistics Report. from http://www.cno.org/en/ what-is-cno/nursing-demographics/regulation-and-legislation/.

College of Nurses of Ontario, b. Frequently Asked Questions About Bill 179 Retrieved from http://www.cno.org/new/notices/bill179 update.htm.

Cruz, D., Pimenta, C., Lunney, M., 2009. Improving critical thinking and clinical reasoning with a continuing education course. Journal of Continuing Education in Nursing 40 (3), 121-127.

DiCenso, A., Auffrey, L., Bryant-Lukosius, D., Donald, F., Martin-Misener, R., Matthews, S., Opsteen, J., 2007. Primary health care nurse practitioners in Canada. Contemporary Nurse 26 (1), 104-115.

Friedlander, E.A., 2006. Online continuing nursing education: A study of factors related to nurse practitioner participation (Doctoral dissertation, Capella University). Retrieved from http://libaccess.mcmaster.ca/login?url=http://search.proquest.com/docview/ 304908494? accountid $=12347$.

Green, R., Gorzka, P., Kodish, S., 2005. Achieving excellence in practice: A model for continuing education for nurse practitioners. Journal of the American Academy of Nurse Practitioners 17 (11), 452-459. http://dx.doi.org/10.1111/j.1745-7599.2005.00075.x.

Health Force Ontario, . Nurse Practitioners. Retrieved from http://www.healthforceontario. ca/whatishfo/faqs/nursepractitioners.aspx.

Hegney, D., Tuckett, A., Parker, D., Robert, E., 2010. Access to and support for continuing professional education amongst Queensland nurses: 2004-2007. Nurse Education Today 30 (2), 105-208. http://dx.doi.org/10.1016/j.nedt.2009.06.015.

Kaasalainen, S., Martin-Misener, R., Kilpatrick, K., Harbman, P., Bryant-Lukosius, D., Donald, F., DiCenso, A., 2010. A historical overview of the development of advanced practice nursing roles in Canada (special issue) Nursing Leadership 23, 35-60.

Kleinpell, R., Bruinsma, S., 2010. E-learning resources for acute care nurse practitioners. The Nurse Practitioner 35 (1), 12-13. http://dx.doi.org/10.1097/ 01.NPR.0000366127.52987.03.

Koren, I., Mian, O., Rukholm, E., 2010. Integration of nurse practitioners into Ontario's primary health care system: Variations across practice settings. Canadian Journal of Nursing Research 42 (2), 49-69.

Mancuso-Murphy, J., 2007. Distance education in nursing: An integrated review of online nursing students' experiences with technology-delivered instruction. Journal of Nursing Education 46 (6), 252-260.

Martin-Misener, R., Bryant-Lukosius, D., Harbman, P., Donald, F., Kaasalainen, S., Carter, N., Kilpatrick, K., DiCenso, A., 2010. Education of advanced practice nurses in Canada. Canadian Journal of Nursing Leadership 23 (Special Issue), 61-84.

Newman, C., Buckley, T., Dunn, S., Cashin, A., 2009. Preferences for continuing education through existing electronic access for Australian nurse practitioners and its implication in prescribing potential. Collegian 16, 79-83. http://dx.doi.org/ 10.1016/j.colegn.2008.10.001.

Penz, K., D'Arcy, C., Stewart, N., Kosteniuk, J., Morgan, D., Smith, B., 2007. Barriers to participation in continuing education activities among rural and remote nurses. Journal of Continuing Education in Nursing 38 (2), 58-66.

Regulated Health Professions Law Statute Amendment Act, . Ontario Ministry of Health and Long-Term Care. Retrieved from http://www.ontla.on.ca/bills/bills-files/ 39_Parliament/Session1/b179.pdf.

Ruiz, J.G., Mintzer, M.J., Leipzig, R.M., 2006. The impact of e-learning in medical education. Academic Medicine 81 (3), 207-212.

Schweitzer, D.J., Krassa, T.J., 2010. Deterrents to nurses' participation in continuing professional development: An integrative literature review. Journal of Continuing Education in Nursing 41 (10), 441-447. http://dx.doi.org/10.3928/00220124-20100601-05.

Sheperd, J.C. 1995. Findings of a training needs analysis for nurse practitioners. Journal of Advanced Nursing 22, 66-71. http://dx.doi.org/10.1111/j.1365-2648.1995.tb00995.x.

Southernwood, J., 2008. Distance learning: The future of continuing professional development. Community Practitioner 81 (10), 21-23.

Stoten, S., 2007. Using podcasts for nursing education. Journal of Continuing Education in Nursing 38 (2), 56-57.

Tilleczek, K., Pong, R., Caty, S., 2005. Innovations and issues in the delivery of continuing education to nurse practitioners in rural and northern communities. Canadian Journal of Nursing Research 37 (1), 146-162.

Van Soeren, M.H., Andrusyszyn, M., Laschinger, H.K.S., Goldenberg, D., DiCenso, A., 2000. Consortium approach for nurse practitioner education. Journal of Advanced Nursing 32 (4), 825-833.

\section{References}

Billings, D., 2009. Wikis and blogs: Consider the possibilities for continuing nursing education. Journal of Continuing Education in Nursing 40 (12), 534-535. http:// dx.doi.org/10.3928/00220124-20091119-10. 